\title{
SUPPORTING OF REPAIRS PROCESSES OF CONCRETE INDUSTRIAL FLOORS
}

\author{
Marcin GAJZLER \\ Institute of Structural Engineering, Poznan University of Technology, \\ Piotrowo 5, 60-965 Poznan, Poland
}

Received 20 December 2015; accepted 16 March 2016

\begin{abstract}
In the large-scale facilities, including on-site storage or shopping malls, floor plays an important role. It has to meet special requirements regarding mechanical properties, aesthetics and durability. Despite much effort, both in the design and execution phase, cases of damage of the floor happens, causing some specific consequences - often associated with restrictions on use. In such a situation it is required to perform rapid diagnosis and effective repair. One possibility foster this process is the use of advisory system which operates in terms of material and technological solutions. The article points out the limitations resulting from the use of advisory system related to situations of individual and unique damage. In the case of such damage it is necessary to implement research procedures and the use of advisory system turns out to be ineffective.
\end{abstract}

Keywords: repair of industrial floors, advisory systems, decision support systems.

\section{Introduction}

Industrial floor is an extremely important part of the object. Its condition is associated with the possibilities of full and proper use of the entire facility. In the case of the analyzed storage facilities, halls, stores, or shopping malls, the floor is subjected to impacts connected with use, during construction of the building by the loads connected with external factors (wind load, snow) and occasionally loads related to internal transport (e.g. the movement of cranes ) (Table 1) (Czarnecki, Skwara 2000; Ganguly, Chatterjee 2015). In such a situation the floor plays an essential feature affecting the usefulness of the object, and object structure is a "cap" on the use function, isolating it from external factors and providing a stable environment inside. Industrial flooring is often an element of finish the object

Table 1. Examples of the typical types of loads for buildings, warehouses (Czarnecki, Skwara 2000).

\begin{tabular}{|c|c|c|}
\hline Load & Impact place & Remarks \\
\hline Wind & The construction of walls and roof & $\begin{array}{c}\text { Variable load; the vertical component } \\
\text { (roof) and horizontal (wall) }\end{array}$ \\
\hline Snow & Roof & Variable load; the vertical component (roof) \\
\hline $\begin{array}{c}\text { Internal transport (movement of cranes, } \\
\text { forklifts and other means of transport) }\end{array}$ & $\begin{array}{c}\text { The construction of pillars, roof girders, } \\
\text { dedicated design, floor, subsoil }\end{array}$ & $\begin{array}{c}\text { Variable load; vertical and horizontal } \\
\text { component }\end{array}$ \\
\hline $\begin{array}{c}\text { Use load (depending on } \\
\text { the destination object) }\end{array}$ & The floor and the subsoil & Variable load; the vertical component \\
\hline Deadweight of the construction & The construction of the object, subsoil & The static load, the vertical component \\
\hline
\end{tabular}

Corresponding author:

M. Gajzler E-mail: marcin.gajzler@put.poznan.pl 
which cause additional requirements of a technical and aesthetic nature. It is particularly important for objects like shopping malls, where investors pay close attention to detail and quality of the floor. Another important element is the stability of the applied solution. Durability is a key element for the exploitation phase, allowing for the preservation and reliable performance flooring conferred during design and construction. Taking into account the sustainability of its service life, and the nature of this stage, the phenomenon of damage or defects connected with flooring is undesirable, and also carries a negative impact on multi-faceted dimension of facility management (technical aspect, the economic, environmental and social) (Gajzler 2013, 2015).

\section{Non-technical aspects}

Despite taking into account at the design stage characteristic values of loads, investor expectations, and best efforts, the situations of workmanship defects, and floors defects happens. The genesis of these damages can be sought in the mistakes in design, errors connected with regulations (improper or non-performance technology, wrong choice of materials) and finally errors and omissions during operations (Czarnecki, Emmons 2002; Littmann 2014; Weldon 2015). In the event of significant damage of the floor, it is often necessary to deactivate the surface of use, which directly can be translated into a certain loss for the owner and the user of the object. In addition to this loss, the next step is to repair it. There are a number of other factors adversely affecting that point, which impact is immeasurable and difficult to predict, eg. the loss of potential orders, reduced credibility etc. For the situation of damage to the floor the costs associated with the repair are countable. Countable are also losses resulting from the need to exclude parts of the surface, which directly influence on the function of the object. It can be described on the example of a storage facility, where off area results in the need to regroup stored materials. It is different in the production facility, where off part of the surface can cause disturbances in the production process and often lowering its efficiency and even its partial exemption. This situations are exceptional and at all costs they should be avoided. Based on the case of damage to the floors in the object like shopping mall, an analysis of the costs was performed (Slosarczyk, Gajzler 2015). The reasons for this damage can be traced to improper performance of the material and of the specific phenomenon of corrosion, which will be commented later in the article. Below there are the costs and losses related to the emergency situation (Fig. 1), as well as distribution graph diagram of costs and revenues in the event of failure the floor during the operational phase (Fig. 2).

The chart shows clearly that the occurrence of damage to the floor generates the cost related to the repair process, which is based on available simplified costing and evaluation methodologies. On the other
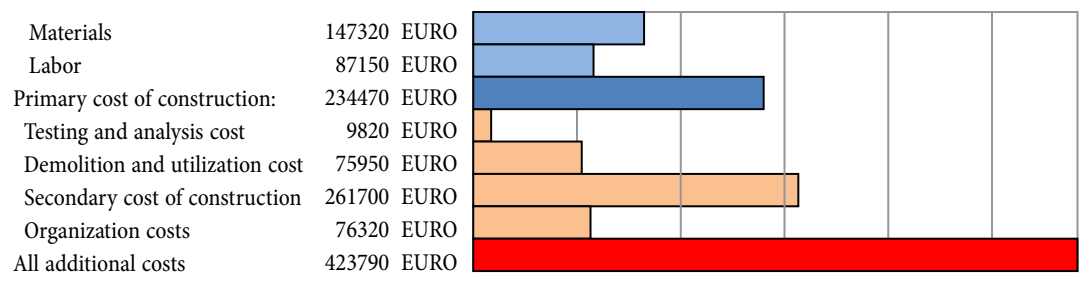

Fig. 1. Summary of the costs and losses for damage to the floor in the shopping center $\left(11.120 \mathrm{~m}^{2}\right)$ (own study)

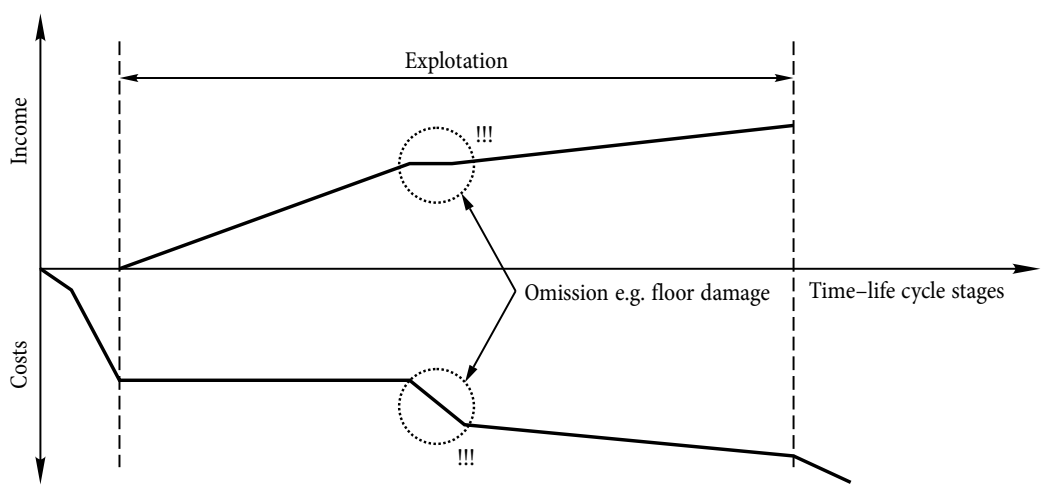

Fig. 2. Diagram chart the distribution of costs and revenues in the event of failure in functioning facility (own study) 
hand they are also generated organizational costs, which for certain cases can be estimated (rearrangement of goods, closure of storage zone). The costs that are difficult to calculate or or even impossible to calculate happens, which are related to the deterioration of the client relationship (a loss of confidence and credibility in relation to the failure rate object).

\section{Technical aspects}

Industrial floors are subjected to many impacts and are naturally subjected to wear. The magnitude of impact can have sometimes extreme dimension, it may cause damage to the floor, which is not linked to the natural processes of aging and wear and tear. Type of actual impact directly depends on the function of the object. Among many types of objects, high-bay warehouses was analyzed in detail in this article. Interactions which occurs are primarily static loads from supports rack components, the traffic load forklifts, as well as the specific burden of a specific object (eg. heat for cold storage facilities / freezers, and chemical in connection with the storage of materials chemically aggressive).

Despite a well-established terms which describes the impact from the floor in the analyzed sites, the cases of damage to the floor happens. Most often they results from: overload (eg. shelving components are expanded or changed in the object), incidental events (eg. falling heavy objects, damage to packaging materials which are chemically aggressive), negligent maintenance (eg. minor damage during use results later in more serious damage). In the analysis the effects of design errors or workmanship were omitted, and author assumes that that at the stage of the investment process there were committed no misconducts. The focus was put on the stage of exploitation.

The result of the previously described situation (congestion, incidents) are damages. These can be, from the point of view of a nuisance, classified as insignificant and significant. As important we take those which restrict the functionality of the facility and require immediate repair works, while irrelevant ones are that at the time of injury do not place any restrictions and do not require immediate repair work conduct. At the same time, there is a need to be aware that damage of a non-significant at a given time may change its character and then will be necessary to carry out the repair work, and even they themselves can then limit the functionality of the facility.

\section{3.. Repairs process in problem of decision making supporting}

In terms of industrial flooring repairs it can be concluded that the repair process is usually an algorithm (Fig. 3) (Czarnecki, Emmons 2002; Sipple 2005). Onsite checking is always necessary to assess damage. This is accompanied by the analysis of the mechanism of damage, as well as the search for causes and attempt to either eliminate or limit them. In the absence of such a possibility, it is necessary to repair and during the reconstruction to take into account new conditions of interactions. In the course of these activities various information are obtained about both the damage and the conditions under which it arose. On the basis of this information and subjected to preferences of the decision maker, repair solution is determined. It is important firstly to choose strategies and material and technological solutions. In terms of material and technological solutions on the market there are many variations. With the majority of which is related to a producer who often offers support in the form of a technical advisor. To some extent this function of supporting of the process of repair can take advisory system.

In the process of recovery decision-making process is visible, which occurs in virtually every element of the recovery algorithm. Starting with the decision to carry out the same repair (as this one may prove ineffective technically or economically), the choice of solutions, material and technology for a decision as to the organization of the repair process (choice as to the conditions of implementation of repair, need to disable the surface, need to regroup materials or halt the processes taking place in the premises) (Gajzler 2010, 2011).

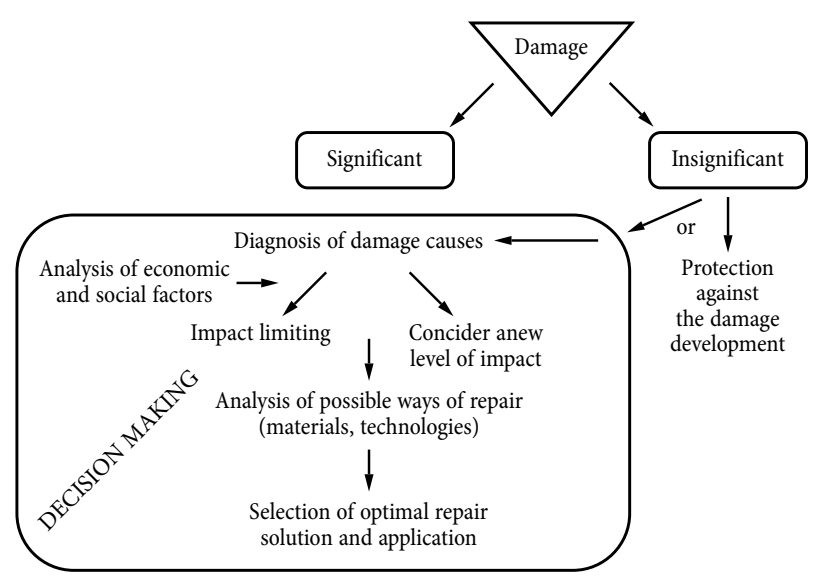

Fig. 3. The simplified repair algorithm (Czarnecki, Emmons 2002) 
Using advisory system, there is a need to reckon with the restrictions resulting from it. Despite classification of expert systems as an instrument from the group of intelligent, author's experience indicates that this relates generally to the cases of failures typical of recurrent character, where the cause of damage are known and are readily identifiable. This conclusion results from the analysis of any use of advisory system for repairing concrete industrial floors (Hybrid Advisory System for Industrial Flooring Repairs) (Gajzler 2010, 2011). The system was tested on simple cases of damage in storage facilities. HASIFR example of the system will be presented later.

Complex cases of damage require an individual analysis of the possible causes and further possible corrective actions. In such situations, there are legitimate concerns that the knowledge base contained in the advisory system may be insufficient to support decision-making processes related to the repair process. This is due to the fact that in the process of building a knowledge base is used in conventional and consistent instances of damage and the resulting consequences. When it is meets a case for which new and individual causes damage occurred, new conditions degradation, new condition of processes, and knowledge base does not contain them, it may happen that even generalization contained in the knowledge base is insufficient.

\section{Case study}

First of the analyzed cases of damage relates to highbay storage facility in the petrochemical industry (automotive chemicals). The property has experienced the impact of mechanical derived from the support rack storage and movement of vehicles, including forklifts.
These interactions, in particular, cause damage to the overload shelves in the form of scratches and cracks in the floors. This phenomenon is the result of exceeding the originally projected at the design stage floor load condition (Fig. 4., a). Vehicles created damage resulted from the interaction of vehicle wheels and frequently appeared on the edges of the joints, which underwent crack and crushing. Both the cracks, and crushing constitute a further possibility of degradation of the floor. Although the state did not constitute a significant damage, but the combination of this state of neglect and misconduct that occurred in the economy component (damaged containers, spill) caused the damage penetrated to these aggressions that led to further degradation (Fig. 4., b). The result was damage in the form of floor surface delamination, which already require significant remedial treatments. This in turn resulted in the need for turning off the surface of use.

This case is a fairly common mechanism of damage, therefore, in order to assist the decision making process associated with the process of reorganization, advisory system was used. The idea of the functioning of the advisory system is shown in Figure 5. In order to use it there was a need to perform dialogue with the system, where in response to questions asked by the system, user defined the input vector. This vector encoded information such as: the type, extent of damage, size of current mechanical loads in a building object, influences of chemical environment, thermal loads, duration of influences, possible temperature for applying a repair material, possible time of repair and related possibilities of a close-down (limitations of influences). Then, within the framework of the system input vector by hitting into the mechanism of the ap-
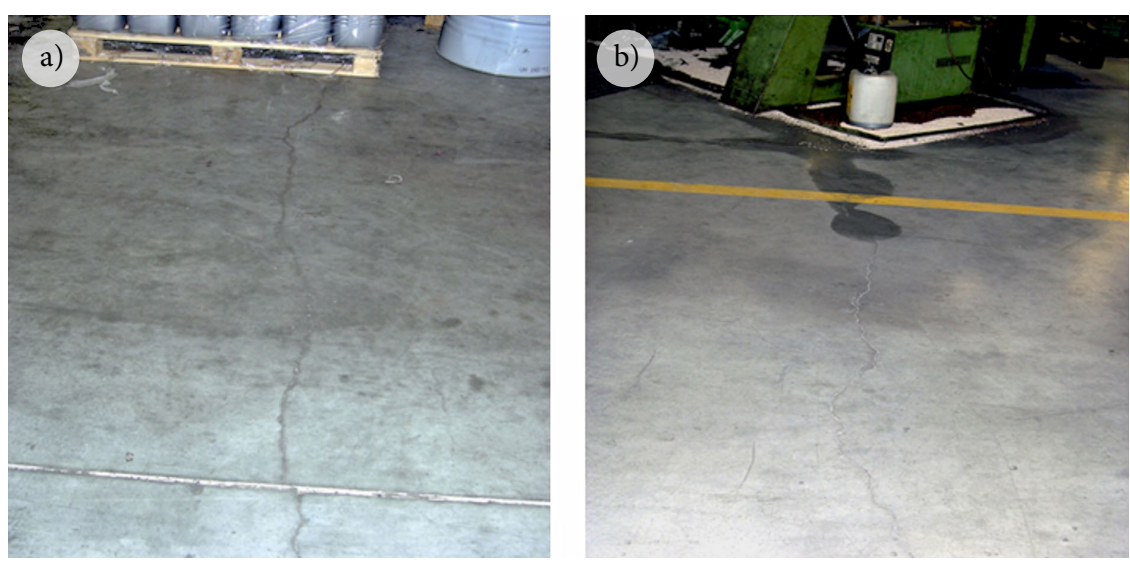

Fig. 4. Examples of damage to the floor of the storage facility the petrochemical industry: $\mathrm{a}$ - crack concrete floors; $\mathrm{b}$ - oiling and penetration cracks in the floor (own study) 


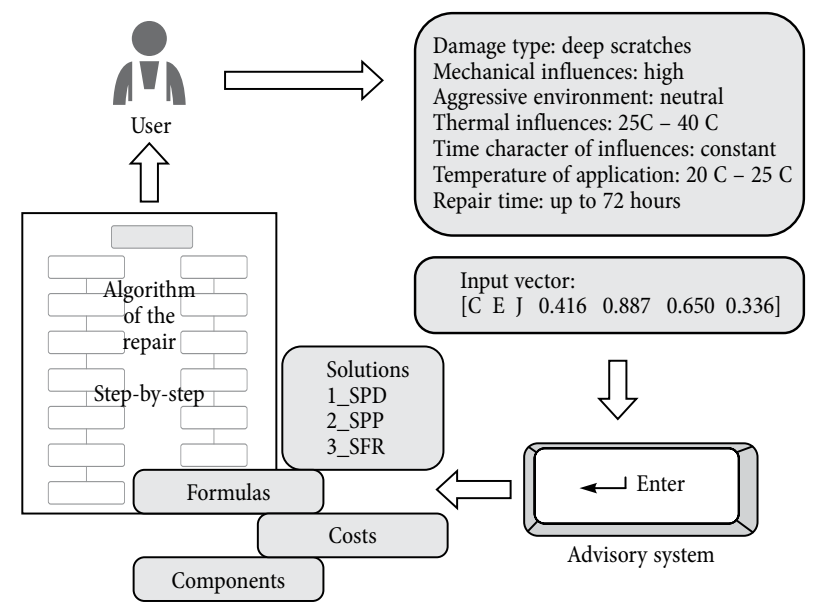

Fig. 5. The idea of the functioning of the advisory system for repairing industrial floors (own study)

plicant (served this function artificial neural networks associated with fuzzy knowledge base used for learning network) output vector is generated, under which proposals were coded by system regarding the possibility repair the damage. Later the specific solutions for the material was generated by algorithm of repair and additional - costs, the needed for specific regimes.
Obtained in this way information was useful guidance for the decision-maker (eg. facility managers) about the possibility of carrying out repairs.

The second of reported cases of damage relates to the floors in the building-shopping mall. Both in the design and execution of floors significant errors were not committed. Because of the large area of $11120 \mathrm{~m}^{2}$ in the facility was designed and executed correct expansion joints, and the whole area was covered with tiles of $50 \mathrm{~cm} \times 100 \mathrm{~cm}$ with adequate strength parameters and in accordance with expected by the investor aesthetics. Even before the release of the object, and soon after it opened tiles began to spontaneously crack. During the analysis, mechanical overload was excluded, as well as regulations and design errors. Solution floor had to be classified as typical and repetitive like in the similar objects. Problems connected with common causes of damage were excluded and other individual were explored. First, the ground - a layer of mortar - ceramic tile system was analyzed. Adhesion tests were performed using the pull-off apparatus (Sadowski, Hola 2014). Studies have shown abnormally low adhesion (Table 2) (Fig. 6).

Table 2. The results of the adhesion of ceramic tiles to the surface in a three-layer system using the pull-off apparatus (own study)

\begin{tabular}{|c|c|c|c|c|c|c|c|}
\hline & \multicolumn{9}{|c|}{ Length of sample sides $\mathrm{a}^{*} \mathrm{~b}^{*} \mathrm{c}^{*} \mathrm{~d}$} & $\begin{array}{c}\text { Surface area of sample } \\
{[\mathrm{mm}]}\end{array}$ & $\begin{array}{c}\text { Breaking force } \\
{[\mathrm{kN}]}\end{array}$ & $\begin{array}{c}\text { Adhesiveness } \\
{\left[\mathrm{N} / \mathrm{mm}^{2}\right]}\end{array}$ \\
\cline { 2 - 9 } & $\mathrm{a}$ & $\mathrm{b}$ & $\mathrm{c}$ & $\mathrm{d}$ & $\mathrm{A}$ & $\mathrm{F}$ & $\mathrm{P}$ \\
\hline Sample B & 58 & 56 & 57 & 58 & 3271 & 2,0 & 1,8 \\
\hline Sample C & 56 & 59 & 56 & 60 & 3337 & 2,1 & 0,61 \\
\hline Sample D & 62 & 60 & 58 & 59 & 3020 & 3,1 & 0,54 \\
\hline Sample E & 64 & 62 & 65 & 60 & 3960 & 1,9 & 0,69 \\
\hline Sample F & 55 & 55 & 57 & 55 & 3096 & 1,2 & 0,62 \\
\hline Sample G & 56 & 58 & 56 & 60 & 3321 & 2,2 & 0,36 \\
\hline Sample H & 55 & 62 & 55 & 61 & 3377 & & 0,65 \\
\hline
\end{tabular}
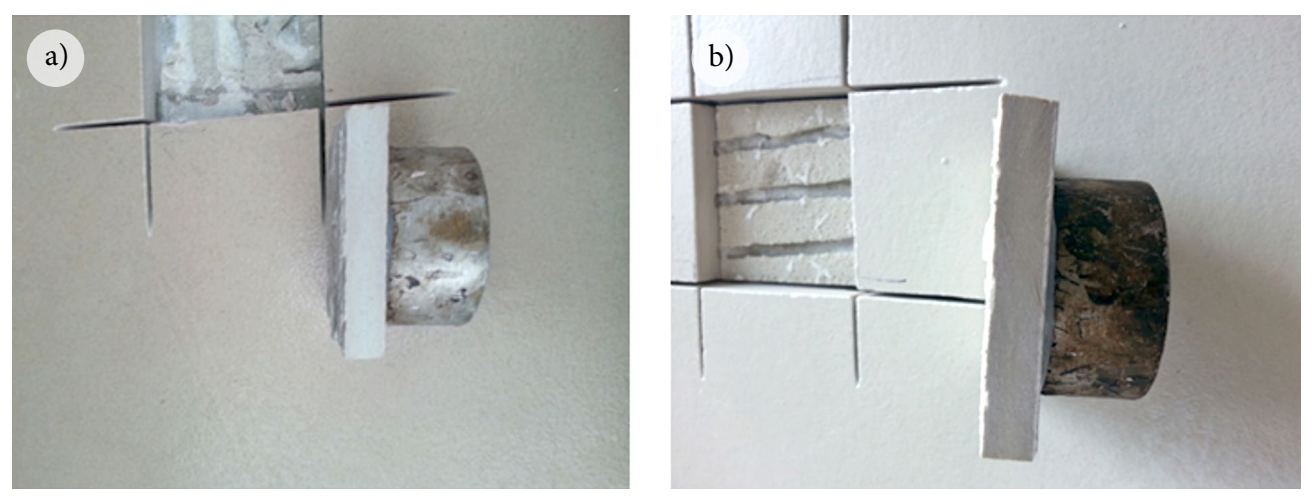

Fig. 6. Exterior samples taken after the adhesion test - breaking the adhesive: $\mathrm{a}$ - left side; $\mathrm{b}$ - right side 
In addition, during the study, white color of macroscopic hydrated mortar was found as well as its relatively large dust level. Originally a type of mortar used was based on the classic mortar (gray) cement binder. The first suspicions about the reasons were directed on the properties of the mortar. Manufacturer of material declared suitable property parameters for use in the facility. Based on this the thesis of the wrong type of good material for flooring was eliminated. The material was subjected to extensive testing in laboratory (Slosarczyk, Gajzler 2015). There was performed study on the elemental composition using scanning probe microscopy, EDS and phase composition from the use of retgen-structure XRD. Furthermore, an microscopic characteristics using a scanning electron microscope SEM was performed. While the study of the elemental composition showed no abnormalities compared to conventional adhesives, other problems were noted:

- High porosity - were observed a large number of times of irregularly shaped occurring hydrated weight of the binder (SEM examination) (Fig. 7).

- The presence of calcium hydroxide, calcium carbonate in the form of calcite, gypsum, clay, calcium carbonate, calcium silicates and thaumasite (XRD test)

Based on the above, and in particular of the compound of the chemical composition corresponding to thaumasite mineral (Sanches de Rojas et al. 2009) as well as of other conditions related to the environment (which can not be classified as special conditions) it was found that the material mortar was under process chemical corrosion, which resulted in changes structural drastic reduction in adhesion and as a result loosening up floor ceramic tiles.

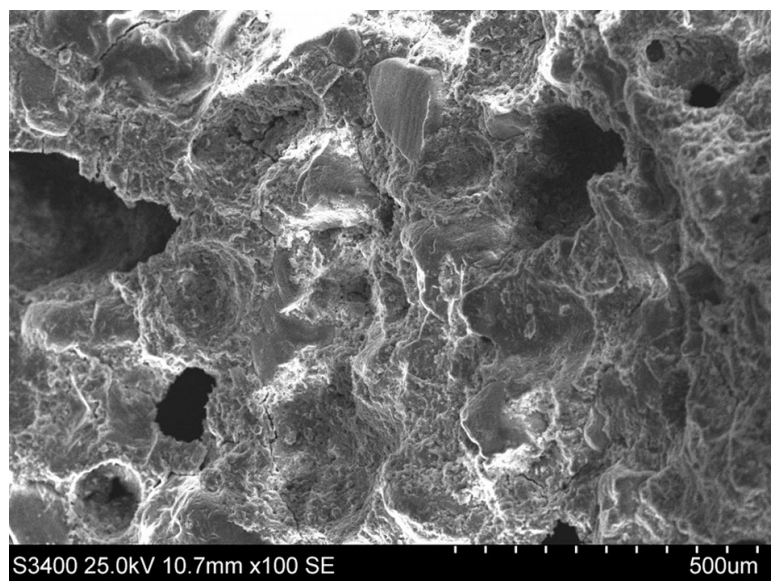

Fig. 7. SEM image of the sample taken from object
This example shows bespoke damage to the floor and the need for individual research program to look for the origin of the problem. In such situations the advisory system is debatable, since it is unlikely that for such individual circumstances, the system generates accurate conclusions.

\section{Conclusions}

Damage to floors and their consequences can be classified as relevant and irrelevant. In addition, key support for the process of corrective actions is the nature of damage - whether it is repeatable or individual. It determines the ability to use tools like - advisory systems. Analysis of a number of cases leads to the conclusion that using advisory system is beneficial- speed and usability especially for users not specialized in repairs as a tool of first contact. At the same time it can be pointed that there are significant restrictions on the use of such a system. In the case of complex failures of individual and unusual causes advisory system exhibits a lower usefulness than conducting individual studies and research.

\section{References}

Czarnecki, L.; Emmons, P. 2002. Repair and protection of concrete structures (in Polish). Polish Cement, Cracov.

Czarnecki, L.; Skwara, J. 2000. Damage and repair of industrial floors, Building Materials 9/2000: 74-80 (in Polish).

Gajzler, M. 2010. Hybrid advisory system for the process of industrial flooring repairs, in A. Zingoni (Eds.). Advances and Trends in Structural Engineering, Mechanics and Computation. London: Taylor \& Francis Group.

Gajzler, M. 2011. Neural networks in the advisory system for repairs of industrial concrete floors, Computer Assisted Mechanics and Engineering Sciences 18: 255-263.

Gajzler, M. 2013. The support of building management in the aspect of technical maintenance, Procedia Engineering 54: 615-624. http://dx.doi.org/10.1016/j.proeng.2013.03.056

Gajzler, M. 2015. Knowledge modeling in construction of technical management system for large warehousing facilities, Procedia Engineering 122: 181-190. http://dx.doi.org/10.1016/j.proeng.2015.10.023

Ganguly, K. K.; Chatterjee, K. 2015. Industrial ground floors, Indian Concrete Journal 89: 55-68.

Littmann, K. 2014. Durability of coatings on industrial floors parameters and examples, Restoration of Buildings and Monuments 20: 183-190.

Sadowski, L.; Hola, J. 2014. New nondestructive way of identifying the values of pull-off adhesion between concrete layers in floors, Journal of Civil Engineering and Management 20: 561-569. http://dx.doi.org/10.3846/13923730.2014.897642 
Sánchez de Rojas, M. I.; Sotolongo, R.; Frías, M.; Marín, F.; Rivera, J.; Sabador, E. 2009. Decay of pavement mortar due to thaumasite formation, Journal of Chemical Technology and Biotechnology 84: 320-325.

http://dx.doi.org/10.1002/jctb.2041

Sipple, H. 2005. Schadensfall: Industrieboden, Betonwerkund Fertigteil-Technik 2/2005.
Slosarczyk, A.; Gajzler, M. 2015. Technical expertise. Institute of Structural Engineering, Poznan University of Technology, Poznan.

Weldon, D. G. 2015. Failure of a coated concrete floor, Journal of Protective Coatings and Lining 32: 17-21.

Marcin GAJZLER, PhD C.E., Assistant Professor at Poznan University of Technology, Institute of Structural Engineering, Division of Construction Engineering and Management. Analyst at the stage of solving decision problems in the area of construction engineering. Research interests: decision-making theory, AI methods in construction industry (fuzzy logic, artificial neural networks, advisory systems), methods of knowledge acquisition (data \& text mining), investment process, economic and management in construction. Court expert in construction area. 